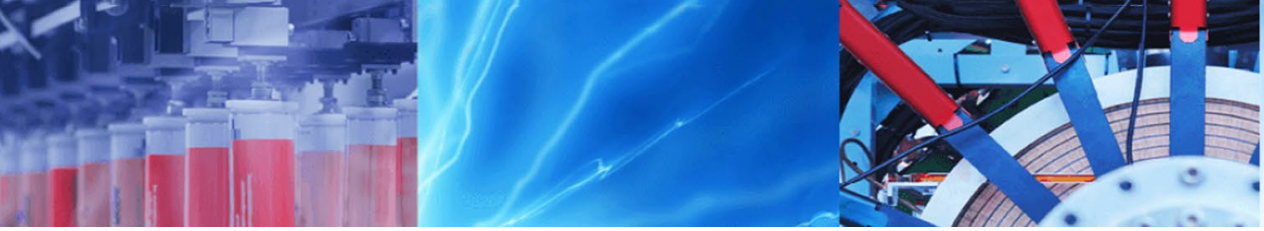

Research Article

\title{
The effect of UV irradiation on polyamide 6/carbon-fiber composites based on three-dimensional printing
}

\author{
Badin Pinpathomrat ${ }^{1} \cdot$ Kazushi Yamada $^{2}$ (D) Atsushi Yokoyama ${ }^{2}$
}

Received: 2 April 2020 / Accepted: 10 August 2020 / Published online: 14 August 2020

(c) Springer Nature Switzerland AG 2020

\begin{abstract}
In this research, we demonstrate the effect of ultraviolet-C (UV-C) irradiation of Polyamide 6/carbon-fiber (PA6/CF) composites. The PA6 and PA6/CF composites were fabricated using a fused deposition modeling type 3D printer with a single spool. These specimens were exposed for $0,1,3,5$, and 7 days under UV-C light irradiation. After exposure, the specimens were observed and characterized with contact angle measurements, Fourier transform infrared analysis, 3D fluorescence spectroscopy analysis, tensile tests, and scanning electron microscopy. As a result, PA6 was found to be more photo-oxidative degraded than PA6/CF. Furthermore, the 3D fluorescence images and emission spectra were shown to successfully coincide with the results of the photo-oxidative degradation reactions of PA6 and PA6/CF. In addition, the tensile test results showed a dramatic decrease in PA6 while PA6/CF did not decrease much, indicating that CF is useful not only as a reinforcement of the composite but also for UV protection.
\end{abstract}

Keywords UV-C irradiation · Degradation · 3D printing · Polyamide 6 - Carbon fiber-reinforced polyamide 6 . Fluorescence spectra

\section{Introduction}

Owing to being a lightweight material with excellent properties such as high specific strength and high specific modulus, carbon fiber is widely used to reinforce composite material for various applications from sports equipment to automobile and aircraft structural parts [1-3]. Carbon fiber also has high heat resistance, a low thermal expansion coefficient, and chemical stability. For this reason, fiber-reinforced composite materials [4-7] are used for structural, thermal, tribological, and environmental applications.

Recently, many researchers have focused on manufacturing processes such as three-dimensional (3D) printing for manufacturing complex shapes at a relatively lower cost than conventional processing methods [8-14]. 3D printing systems have grown rapidly in recent years owing to their low cost, accessibility, and open source technology. This technology is very popular for 3D part creation because it can produce complexly shaped components relatively quickly. Many 3D printer filaments containing carbon fiber, glass fiber, and natural fiber have also been developed to easily print fiber composite products. By using these fiber-containing filaments, the mechanical properties are dramatically improved when compared with molded products made only from matrix resins. Recently developed filaments based on continuous carbon fibers, i.e., PLA/CF [15], PA6/CF [9], and prepreg carbon fibers [16], have enabled the printing of molded products with excellent structural properties as well as mechanical and environmental applications.

$\triangle$ Kazushi Yamada, kazushi@kit.ac.jp | 1 Department of Advanced Fibro-Science, Kyoto Institute of Technology, Matsugasaki, Sakyo-ku, Kyoto 606-8585, Japan. ${ }^{2}$ Faculty of Fiber Science and Engineering, Kyoto Institute of Technology, Matsugasaki, Sakyo-ku, Kyoto 606-8585, Japan. 
Furthermore, while there are examples of research on UV protection of fabric using PEDOT/magnetite nanoparticles [17] and UV protection of transparent cellulose films using carbon dots [18], there are no examples of research on UV protection of carbon-fiber composites, especially concerning the characteristics of degradation by UV-C light irradiation. The evaluation methods for longterm durability tests of polymer composite materials are mainly mechanical tests and thermal properties $[1,19]$. Recently, research on the evaluation of the initial degradation state of polymer materials using the chemiluminescence method has been increasing [20-23]. However, the chemiluminescence method does not measure a sample at room temperature, but rather measures the intensity of chemiluminescence from radical species generated during heating. Consequently, this method does not evaluate the characteristics of materials degradation. Meanwhile, when the polymer material is degraded by light or heat, an oxidized functional group such as a carbonyl group is generated on the surface of the material $[20,24,25]$. The fluorescence spectrophotometer should easily detect the change in fluorescence emission intensity resulting from degradation.

In this research, all specimens were successfully prepared from single filaments of PA6 and PA6/CF using a fused deposition modeling (FDM) type 3D printer. The purpose of this research is to reveal the structural changes resulting from exposure of PA6 and PA6/CF specimens to UV-C light for 0-7 days. Samples were observed and characterized before and after exposure using contact angle measurements, Fourier transform infrared analysis (FT-IR), 3D fluorescence spectroscopy, tensile testing, and scanning electron microscopy (SEM).

\section{Experiment}

\subsection{Materials and sample preparation}

The polyamide (PA6) (Flashforge Co., Ltd., Japan) and PA6/ CF (Shenzhen Esun Industrial Co., Ltd., China) filaments blended with $25 \mathrm{wt} \%$ carbon fibers (CF) of commercial grade were used as materials. The 3D printer used in this study is a GEEETECH A20M dual extruder 3D printer provided by GEEETECH, Ltd., China to prepare the dumbbellshaped specimens with the ISO 8256-2 shape.

\subsection{UV-C light irradiation}

Each sample was placed under a UV-C lamp for 0, 1, 3, 5, and 7 days to induce UV degradation. The UV wavelength is $254 \mathrm{~nm}$, and the UV intensity measured at a distance of $50 \mathrm{~mm}$ from the light source is $2020 \mu \mathrm{W} / \mathrm{cm}^{2}$.

\subsection{Composite characterization}

\subsubsection{Contact angle measurements}

Static contact angle measurement was performed to characterize the wettability properties of a sample surface before and after UV-C irradiation. In this study, SImage AUTO 100 (Excimer Inc., Japan) was used for static contact angle measurement. Contact angles were measured five times for each condition. The average values \pm standard deviations of the contact angles were plotted using five points data. The specifications of contact angle measurements are shown in Table 1.

\subsubsection{Fourier transform infrared analysis (FT-IR)}

The PA6 and PA6/CF composite specimens were characterized before and after UV-C irradiation using an attenuated total reflection (ATR) mode of FT-IR spectroscopy (GX, 2000 FT-IR spectrometer, PerkinElmer, Inc., USA) to measure the changes in functional groups induced through UV degradation to compare them among the specimens. Spectra were collected within the range of $4000-700 \mathrm{~cm}^{-1}$ at a resolution of $4 \mathrm{~cm}^{-1}$, and the number of scans was set at 20 times per sample. FT-IR spectra were measured three times for each condition.
Table 1 Summary of the specifications of contact angle measurements

\begin{tabular}{ll}
\hline Model & SImage AUTO 100 \\
Wettability test method & JIS R3265 \\
Measurement range & $0<\theta<180^{\circ}$ \\
Angular resolution & $0.1^{\circ}$ \\
Contact angle resolution & Tangent line method (auto mode) $\quad \theta / 2$ method (manual mode) \\
Camera & 16 megapixel \\
Capture speed & About $15 \mathrm{fps}$ \\
Dispenser & $2.5-10 \mu \mathrm{L}$ micrometer head control \\
Outer dimensions & W270 $\times \mathrm{H} 290 \times \mathrm{D} 120 \mathrm{~mm}$ \\
\hline
\end{tabular}




\subsubsection{D fluorescence spectroscopy analysis}

The 3D fluorescence spectra were acquired at $25^{\circ} \mathrm{C}$ using a RF-6000 Shimadzu spectrofluorophotometer with a variable excitation wavelength $\left(\lambda_{\text {ex }}\right)$ range of $200-400 \mathrm{~nm}$ and emission wavelength $\left(\lambda_{\mathrm{em}}\right)$ range of $360-600 \mathrm{~nm}$, with an interval of $2.0 \mathrm{~nm}$ for $\lambda_{\mathrm{ex}}$ and $1.0 \mathrm{~nm}$ for $\lambda_{\mathrm{em}}$. The scan speed was set at $6000 \mathrm{~nm} / \mathrm{min}, \lambda_{\mathrm{ex}}$ bandwidth was set at $3.0 \mathrm{~nm}$, and $\lambda_{\mathrm{em}}$ bandwidth was set at $3.0 \mathrm{~nm}$. Samples were prepared before and after UV-C irradiation for up to 7 days for the PA6 and PA6/CF dumbbell-shaped specimens. Excitation and emission spectra for both PA6 and PA6/CF were extracted from the $3 \mathrm{D}$ spectra before and after UV-C irradiation.

\subsubsection{Mechanical tensile tests}

The PA6 and PA6/CF composite specimens were measured with a tensile testing machine to investigate the tensile strength and to compare the mechanical performance of the samples before and after UV-C irradiation. A Table-Top Universal Testing Machine (MCT-2150, A\&D Co. Ltd, Japan) at $25^{\circ} \mathrm{C}$ with $30 \mathrm{~mm}$ of grip distance at a crosshead speed of $50 \mathrm{~mm} / \mathrm{min}$ performed the tensile tests. The average values \pm standard deviations of the tensile strength were evaluated using three independent specimens.

\subsubsection{Scanning electron microscopy (SEM)}

The surface morphology of the PA6 and PA6/CF composite specimens was observed by using a scanning electron microscope (SEM, JSM-6010LA, JEOL Co. Ltd., Japan). The electron accelerating voltage was set at $10-15 \mathrm{kV}$, and the spot size was set at 40 . Before the SEM observations, the specimens were mounted onto aluminum specimen stubs using double-sided adhesive carbon tape and were coated in gold using an ion-sputtering machine (JFC-1600 Auto Fine Coater, JEOL Co. Ltd., Japan).

\section{Results and discussion}

Figure 1 shows the effect of UV-C light irradiation on the surface appearance of PA6 and PA6/CF composites as observed by visual inspection on specimens exposed for a duration of $0,1,3,5$, and 7 days. The color of the PA6 specimens gradually yellows with increasing UV-C irradiation time. The color change may be caused by increasing surface oxidation of the specimens during irradiation exposure. However, the color change is hardly discernible for the black PA6/CF specimens. Therefore, to investigate changes in surface properties, the static contact angle of the sample surface was measured before and after UV-C irradiation.

The structural changes of the PA6 and PA6/CF surfaces before and after UV-C light irradiation are measured by FT-IR. Figure $2 a, b$ shows the FT-IR spectra of PA6 and PA6/CF composite specimens from 3000 to $2800 \mathrm{~cm}^{-1}$ and from 1730 to $1500 \mathrm{~cm}^{-1}$, respectively. In these spectra, we observed absorption bands of $\mathrm{CH}_{2}$ with asymmetric stretching vibrations of approximately 2930 and $2860 \mathrm{~cm}^{-1}$, amides I ( $\mathrm{C}=\mathrm{O}$ stretching) of approximately $1640 \mathrm{~cm}^{-1}$, amide II ( $\mathrm{N}-\mathrm{H}$ deformation and $\mathrm{CN}$ stretching) of approximately $1545 \mathrm{~cm}^{-1}, \mathrm{CH}_{2}$ deformation of approximately $1400-1470 \mathrm{~cm}^{-1}$, amide III (CN stretching and $\mathrm{N}-\mathrm{H}$ deformation), and $\mathrm{CH}_{2}$ wag of approximately 1262 and $1370 \mathrm{~cm}^{-1}$. These peaks mainly reflect the PA6 structure $[26,27]$. Figure $2 c$, $d$ shows the change rate percentage of each peak before and after UV-C irradiation for the PA6 and PA6/CF composite specimens, respectively. In the PA6
Fig. 1 The surface appearance of PA6 and PA6/CF composite specimens before and after UV-C irradiation from 0 to 7 days
PA6 dumbbell type specimens

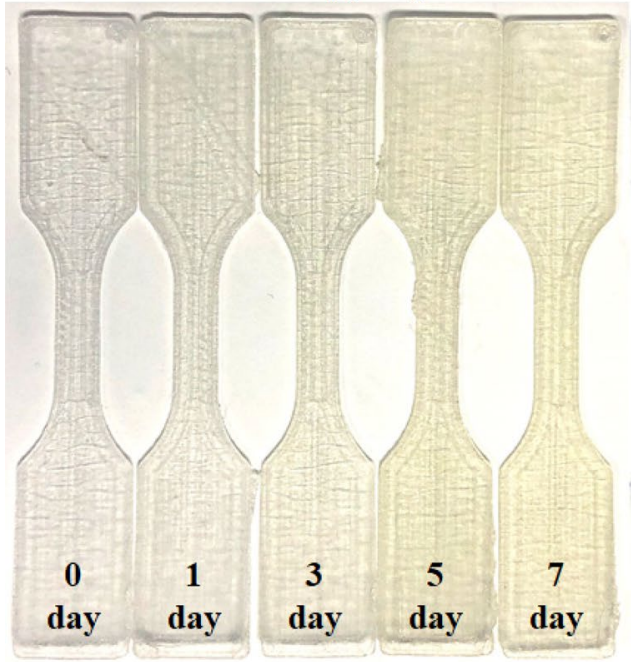

PA6/CF dumbbell type specimens

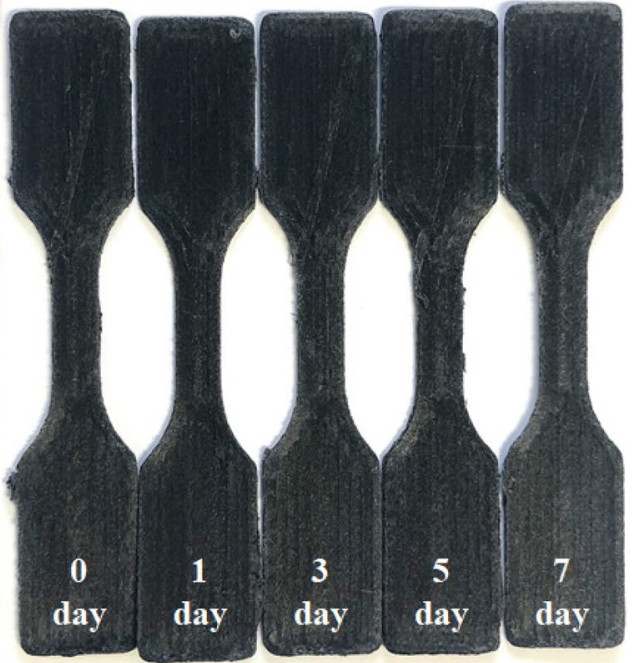



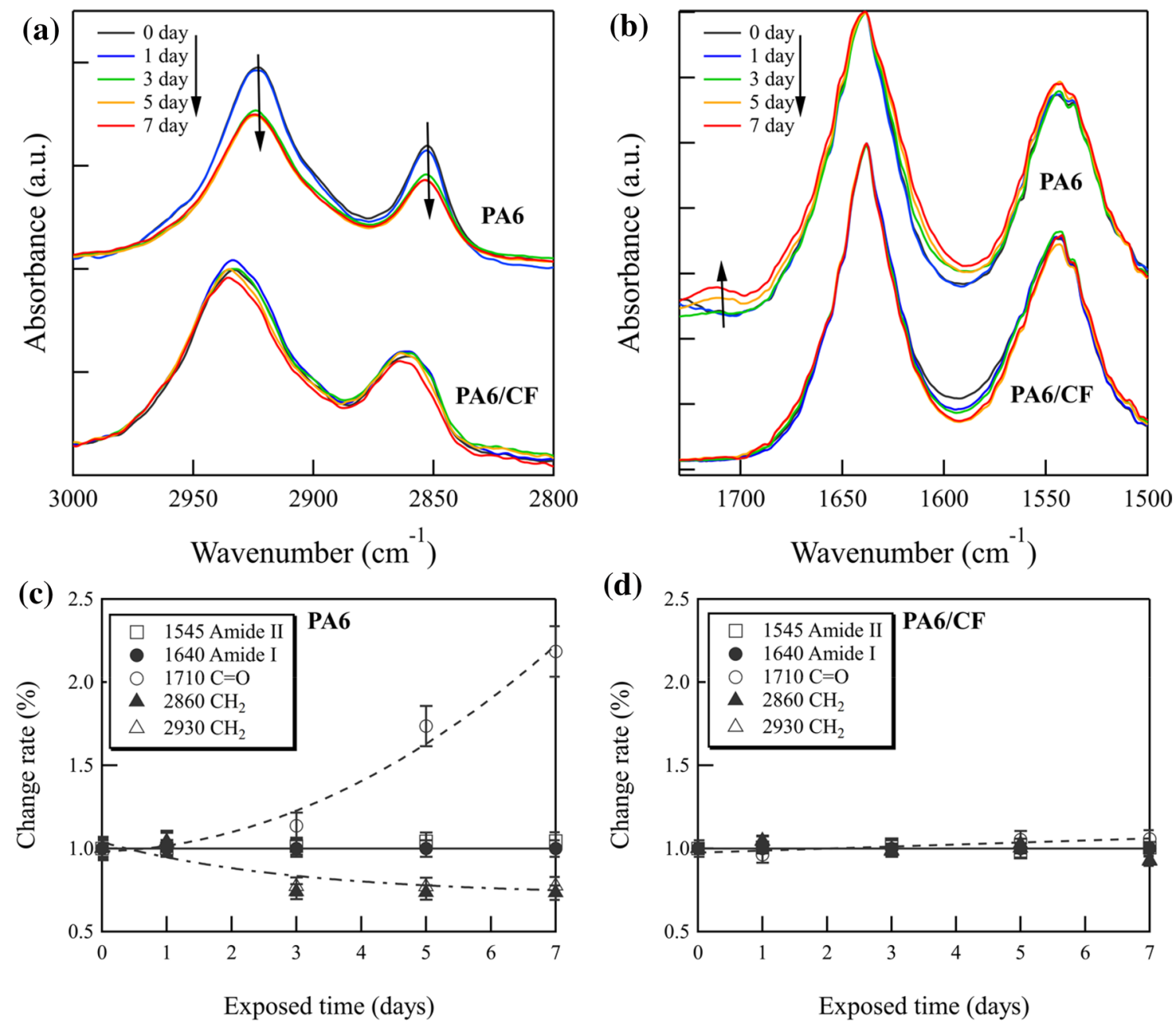

(d)

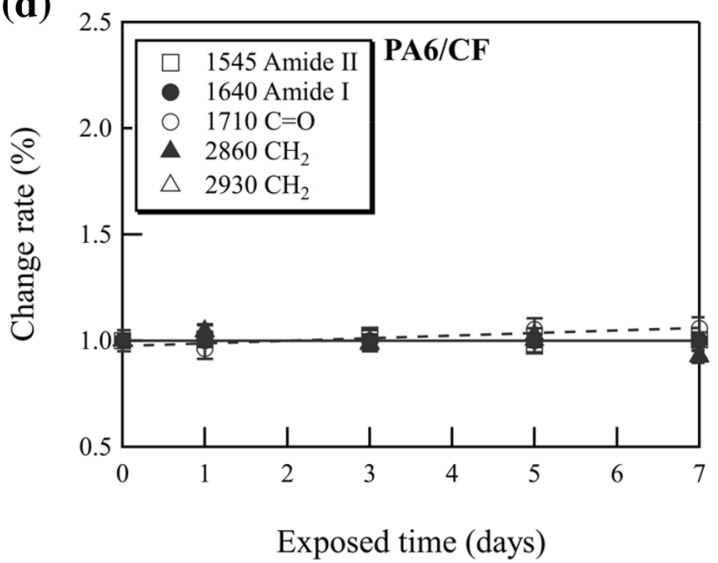

Fig. 2 FT-IR spectroscopy analysis of PA6/Carbon-fiber composites before and after UV-C irradiation: a absorbance of PA6 and PA6/ CF between 3000 and $2800 \mathrm{~cm}^{-1}, \mathbf{b}$ absorbance of PA6 and PA6/CF

spectra, the peaks of amides I and II showed no change, the intensity of the $\mathrm{CH}_{2}$ asymmetric vibration and stretching peaks of 2930 and $2860 \mathrm{~cm}^{-1}$ gradually decreased, and the $C=O$ peak of $1710 \mathrm{~cm}^{-1}$ tended to increase with exposure time. Generally, UV light facilitates the degradation of polymer molecules $[28,29]$. Therefore, these changes are likely attributed to oxidation and degradation by irradiated UV-C light. By contrast, in the FT-IR spectrum of the PA6/CF composite, the $C=0$ peak at $1710 \mathrm{~cm}^{-1}$ increased slightly at 5 and 7 days, whereas the other peaks showed no change before and after UV-C light irradiation. Generally, black color is known to effectively absorb incident light, and the darker surface acts as light-absorbing material $[30,31]$. The absorption of ultraviolet rays by the carbon fiber likely prevents PA6 degradation. Nevertheless, when UV-C irradiation was applied in this experiment, the chemical structure of the surface of PA6 and PA6/CF changed and the peak of carbonyl groups increased. This

between 1730 and $1500 \mathrm{~cm}^{-1}$, c change rate of PA6, and $\mathbf{d}$ change rate of PA6/CF

suggests that the PA6 molecular chain was oxidatively degraded by UV-C [32].

To evaluate the surface property change, we measured the static contact angle. Figure 3 shows the lateral view of a water droplet on the sample and a plotted graph of the static contact angle exposed for $0,1,3,5$, and 7 days to UV-C light irradiation. The contact angles on the surface of the PA6 and PA6/CF specimens before UV-C light irradiation are $41.11^{\circ}$ and $51.73^{\circ}$, respectively. The water contact angles on the PA6 specimens decreased from $41.11^{\circ}$ to approximately $26^{\circ}, 20^{\circ}, 14^{\circ}$, and $13^{\circ}$ after 1,3 , 5 , and 7 days of UV-C light irradiation, respectively. In addition, in the PA6/CF composite specimens, the water contact angles decreased from $51.73^{\circ}$ to approximately $50^{\circ}, 46^{\circ}, 42^{\circ}$, and $40^{\circ}$ after $1,3,5$, and 7 days of UV-C light, respectively. For both PA6 and PA6/CF, the surface contact angle decreased with an increasing number of days of UV-C irradiation. The contact angle decrease is due to 

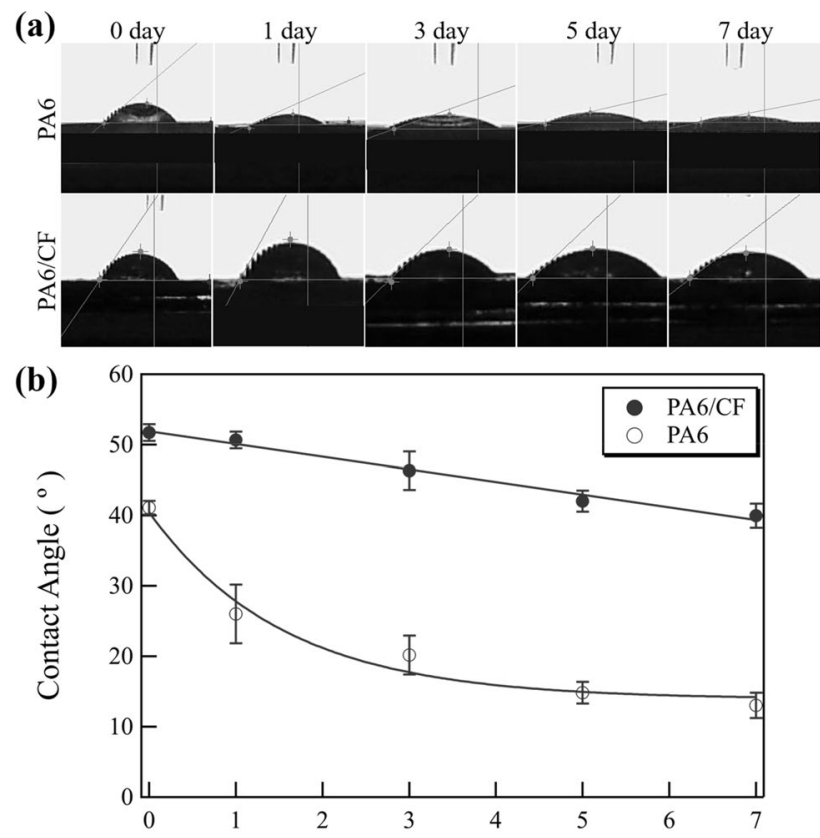

Elapsed Days

Fig. 3 Contact angle measurements: a photographs of water droplets on PA6 and PA6/CF composite specimens, and $\mathbf{b}$ graphical report of contact angle measurements as a function of days photo-oxidation degradation of the sample surface by UV-C light irradiation on the surface of the specimens. The decrease of contact angle was particularly prominent for PA6 specimens. The FT-IR results shown in Fig. 2 support this decrease. Meanwhile, the PA6/CF contact angle probably showed a larger value than that of the PA6 because of partially present carbon fibers on the surface of the PA6/CF composite. Consequently, the surface of the PA6/CF composite showed more nonpolar and hydrophobic properties than the PA6 specimens.

Figure 4a shows 3D fluorescence spectra images of PA6 and PA6/CF composites after UV-C light irradiation as a function of days of exposure for a duration of $0,1,3,5$, and 7 days. In these 3D spectra images, the vertical axis corresponds to the excitation wavelength, the horizontal axis to the emission wavelength, and the red and purple regions to high- and low-intensity emission, respectively. In the case of the PA6 specimens, the wavelength region that emits bright light lengthens with an increase in the number of UV-C irradiation days. Figure $4 \mathrm{~b}$ shows emission spectra at an excitation wavelength of $350 \mathrm{~nm}$. Figure $4 \mathrm{c}$ shows the plotted graph of peak emission wavelength for days exposed to UV-C light. These graphs show that the peak emission wavelength lengthens when exposed to UV-C irradiation. Photo-oxidation causes the red-shifted maximum excitation wavelength from 410 to $455 \mathrm{~nm}$ [33]. However, the 3D fluorescence image of the PA6/CF

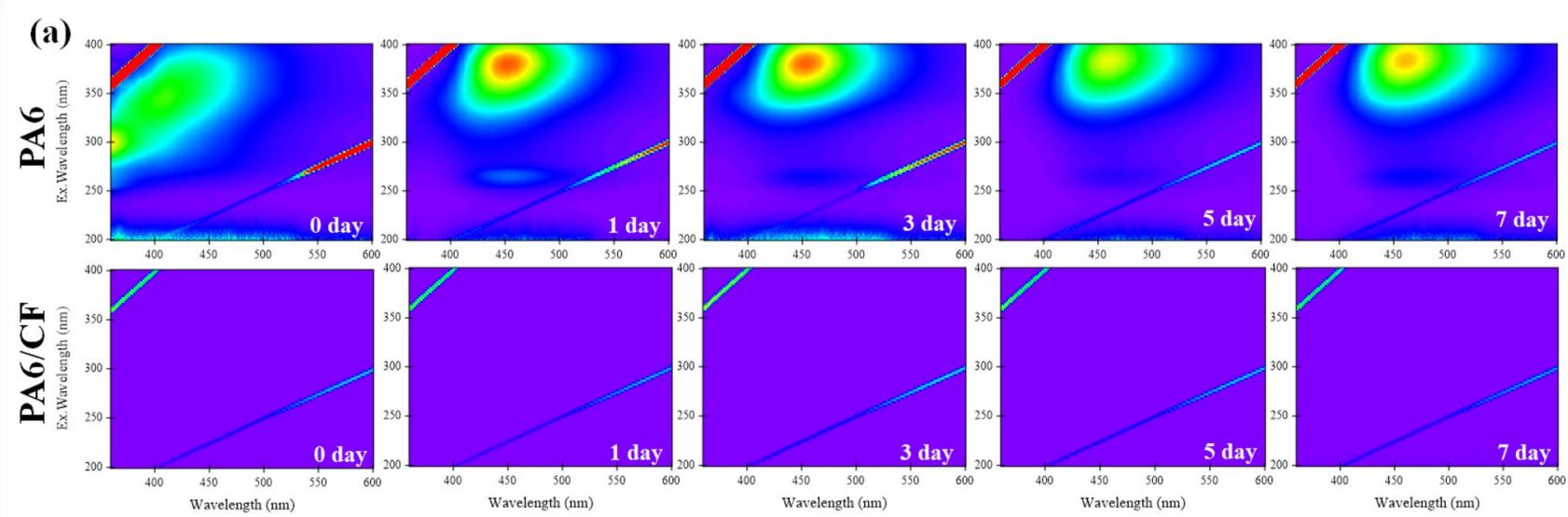

(b)

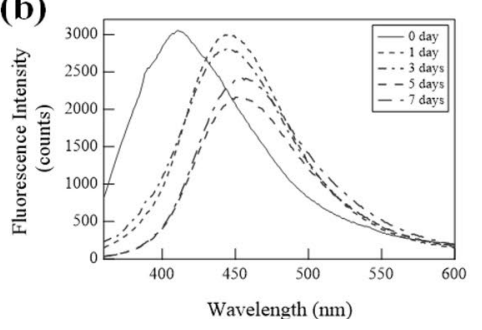

(c)

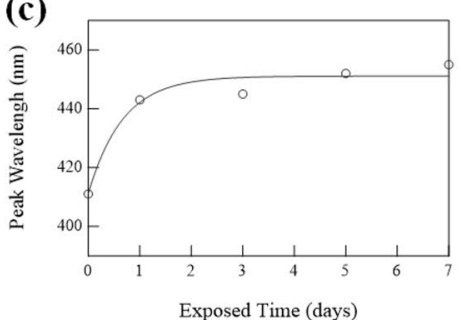

(d)

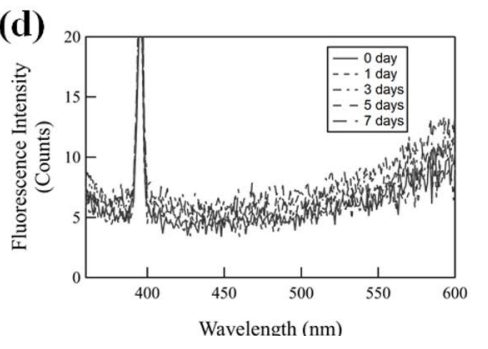

Fig. 4 Fluorescence spectra measurement of PA6 and PA6/CF composites before and after UV-C light irradiation: a 3D fluorescence spectra of PA6 and PA6/CF, b fluorescence spectra of PA6 at $350 \mathrm{~nm}$, c peak wavelength of PA6 for exposed days, $\mathbf{d}$ fluorescence spectra of PA6/CF at $350 \mathrm{~nm}$ 
composite did not show any change regardless of the number of UV-C irradiation days. Figure $4 d$ shows the emission spectra of the PA6/CF composites at $350 \mathrm{~nm}$ where the emission intensity was less than 15 counts with a noise peak at $390 \mathrm{~nm}$. Figure 2 shows that these fluorescence spectral changes with photo-oxidation are similar to the change in $\mathrm{C}=\mathrm{O}$ peak intensity in the FT-IR measurement. Therefore, carbon fibers on the surface play an important role in inhibiting photo-oxidative degradation.

A tensile test evaluated the effect of UV-C irradiation on the mechanical properties of the PA6 and PA6/CF composites. Figure 5 shows the tensile test results before and after UV-C irradiation for the PA6 and PA6/CF composites. The tensile strength of the PA6 specimens decreases significantly with increased exposure days. The stress-strain curves on unirradiated and irradiated specimens on day 1 showed high strength and elongation with a yield point. However, the tensile strength decreased dramatically on the third day of UV irradiation, and gradually decreased thereafter. Because oxidative degradation and hydrolysis tend to make the polymer brittle, the PA6 specimens were more brittle after UV-C light irradiation [34, 35]. However, the PA6/CF composite specimens showed no noticeable difference in tensile strength with increased exposure to

(a)
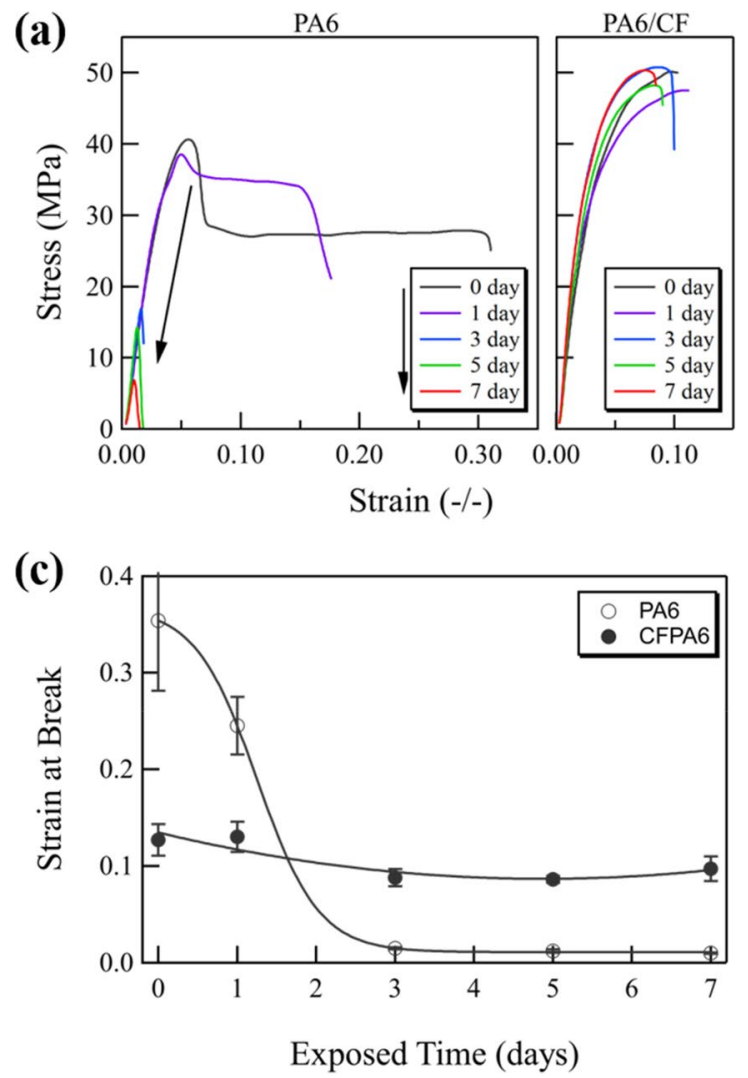

UV-C light irradiation. Conversely, tensile strength appears to have increased slightly with increased exposure to UV-C light. PA6 is a crystalline polymer, and although this research did not include crystallization measurements, accelerated crystallization over time may be responsible for the change in tensile strength.

To evaluate the influence of UV-C on mechanical properties, the sample surface of the composites was observed by SEM. Figure 6a-d shows the SEM micrographs of the PA6 and PA6/CF composite surfaces before and after UV light irradiation, respectively. The PA6 surface before UV-C irradiation ( 0 days) was very smooth, but changed drastically after 7 days of exposure. In addition, some cracks appeared on the surface. Meanwhile, the surface of the PA6/CF composite contained abundant carbon fiber and featured a lumpy surface that did not change after exposure to UV-C irradiation. From the results of SEM observation, it is thought that cracks generated on the sample surface after UV-C irradiation caused the dramatic decrease of the mechanical properties in the PA6. Moreover, there was no decrease of mechanical properties or photo-oxidation degradation for PA6/CF composites after UV-C irradiation. Thus, the material containing the carbon fiber requires neither a light absorber nor an antioxidant that would cause

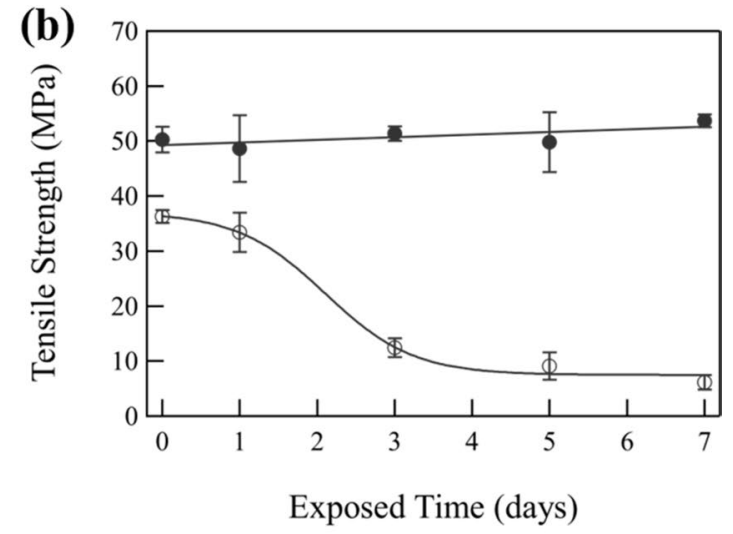

Fig. 5 Mechanical properties of PA6/Carbon-fiber composites before and after UV-C light irradiation: a stress-strain curves, b tensile strength, and c strain at break 
Fig. 6 SEM micrographs of the surface of PA6 and PA6/CF specimens before and after UV light irradiation: a PA6 ( 0 days), b PA6 (7 days), c PA6/CF (0 days), and $\mathbf{d}$ PA6/CF (7 days). Yellow color circles correspond to cracks
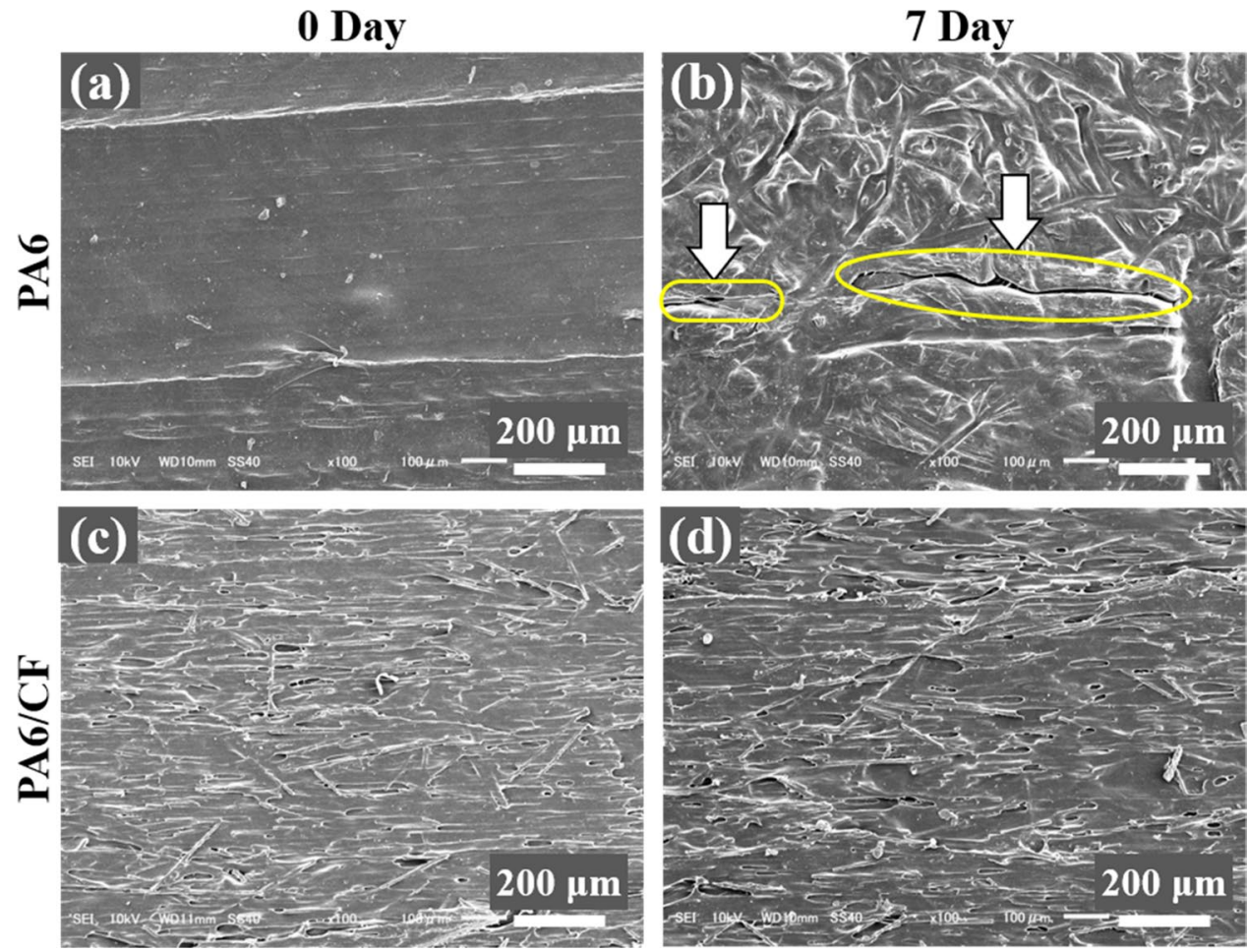

oxidative deterioration. Carbon fiber has been shown not only to act as a mechanical reinforcement for the resin, but also to help prevent photo-oxidative degradation.

\section{Conclusions}

This research aims to provide novel strategies to improve the mechanical properties of ultraviolet light resistance materials by adding carbon fiber. Here, we have successfully produced PA6/CF composite products with a 3D printer and carried out accelerated degradation tests with UV-C irradiation. Static contact angle measurements FT-IR then evaluated the change in surface properties after UV-C light irradiation. In the results of FT-IR after UV-C exposure, for the PA6, the intensity of the $\mathrm{CH}_{2}$ asymmetric vibration and stretching peaks of 2930 and $2860 \mathrm{~cm}^{-1}$ gradually decreased, and the carbonyl group peak of $1710 \mathrm{~cm}^{-1}$ tended to increase with exposure time, while the peak intensity change of PA6/CF shows only a slight increase in the carbonyl group and a slight decrease in the $\mathrm{CH} 2$ asymmetric vibration and stretching peaks. For both PA6 and $P A 6 / C F$, the contact angle decrease is due to photooxidation degradation of the sample surface by UV-C light irradiation on the surface of the specimens. In addition, the results of 3D fluorescence spectroscopy for PA6 showed that the emission peak shifted to longer wavelengths as the number of days of UV-C exposure increased due to photo-oxidation degradation, while no emission peak was observed for PA6/CF. The tensile properties of the PA6 specimens decrease significantly with increased exposure days. However, the PA6/CF composite specimens showed no noticeable difference in tensile strength with increased exposure to UV-C light irradiation. Therefore, carbon fibers on the surface play an important role not only in reinforcing composites, but also in inhibiting photo-oxidative degradation. Additionally, we demonstrated that 3D fluorescence measurements reveal the spectra intensity and wavelength range changes for PA6 samples before and after UV-C irradiation. These results will allow for new evaluation methods of the degradation of polymer materials and composites.

Acknowledgements This work has no funding and was supported by the Kyoto Institute of Technology. The authors thank the Kyoto Institute of Technology for providing necessary facilities.

\section{Compliance with ethical standards}

Conflict of interest The authors declare that they have no conflict of interest.

\section{References}

1. Liu T, Tian X, Zhang M, Abliz D, Li D, Ziegmann G (2018) Interfacial performance and fracture patterns of 3D printed continuous carbon fiber with sizing reinforced PA6 composites. Compos A Appl Sci Manuf 114:368-376. https://doi.org/10.1016/j.compo sitesa.2018.09.001 
2. Sang L, Wang $Y$, Wang C, Peng X, Hou W, Tong L (2019) Moisture diffusion and damage characteristics of carbon fabric reinforced polyamide 6 laminates under hydrothermal aging. Compos A Appl Sci Manuf 123:242-252. https://doi.org/10.1016/j.compo sitesa.2019.05.023

3. Karsli NG, Aytac A (2013) Tensile and thermomechanical properties of short carbon fiber reinforced polyamide 6 composites. Compos B Eng 51:270-275. https://doi.org/10.1016/j.compo sitesb.2013.03.023

4. An HJ, Kim JS, Kim K-Y, Lim DY, Kim DH (2014) Mechanical and thermal properties of long carbon fiber-reinforced polyamide 6 composites. Fibers Polym 15(11):2355-2359. https://doi. org/10.1007/s12221-014-2355-5

5. Li J, Xia YC (2009) The reinforcement effect of carbon fiber on the friction and wear properties of carbon fiber reinforced PA6 composites. Fibers Polym 10(4):519-525. https://doi.org/10.1007/ s12221-009-0519-5

6. Botelho E (2003) Mechanical behavior of carbon fiber reinforced polyamide composites. Compos Sci Technol 63(13):1843-1855. https://doi.org/10.1016/s0266-3538(03)00119-2

7. Hasan MMB, Nitsche $S$, Abdkader A, Cherif C (2018) Carbon fibre reinforced thermoplastic composites developed from innovative hybrid yarn structures consisting of staple carbon fibres and polyamide 6 fibres. Compos Sci Technol 167:379-387. https:// doi.org/10.1016/j.compscitech.2018.08.030

8. Iragi M, Pascual-González C, Esnaola A, Lopes CS, Aretxabaleta $L$ (2019) Ply and interlaminar behaviours of 3D printed continuous carbon fibre-reinforced thermoplastic laminates; effects of processing conditions and microstructure. Addit Manuf. https ://doi.org/10.1016/j.addma.2019.100884

9. Parandoush P, Zhou C, Lin D (2019) 3D printing of ultrahigh strength continuous carbon fiber composites. Adv Eng Mater. https://doi.org/10.1002/adem.201800622

10. Chen P, Wu H, Yang L, Li Z, Yan C, Liu J, Wen S, Shi Y (2019) A 2D correlation infrared spectroscopic study on the temperatureinduced molecular motion mechanism concerning self-formed composite structure of 3D printed PA6. Polymer 167:48-53. https://doi.org/10.1016/j.polymer.2019.01.075

11. Koh JJ, Lim GJH, Zhou X, Zhang X, Ding J, He C (2019) 3D-printed anti-fouling cellulose mesh for highly efficient oil/water separation applications. ACS Appl Mater Interfaces 11(14):1378713795. https://doi.org/10.1021/acsami.9b01753

12. Rodriguez MJ, Dixon TA, Cohen E, Huang W, Omenetto FG, Kaplan DL (2018) 3D freeform printing of silk fibroin. Acta Biomater 71:379-387. https://doi.org/10.1016/j.actbio.2018.02.035

13. Luan C, Yao X, Liu C, Lan L, Fu J (2018) Self-monitoring continuous carbon fiber reinforced thermoplastic based on dualmaterial three-dimensional printing integration process. Carbon 140:100-111. https://doi.org/10.1016/j.carbon.2018.08.019

14. Wang B, Chen X, Ahmad Z, Huang J, Chang M-W (2019) 3D electrohydrodynamic printing of highly aligned dual-core graphene composite matrices. Carbon 153:285-297. https://doi. org/10.1016/j.carbon.2019.07.030

15. Tian X, Liu T, Yang C, Wang Q, Li D (2016) Interface and performance of 3D printed continuous carbon fiber reinforced PLA composites. Compos A Appl Sci Manuf 88:198-205. https://doi. org/10.1016/j.compositesa.2016.05.032

16. Hu Q, Duan Y, Zhang H, Liu D, Yan B, Peng F (2017) Manufacturing and $3 \mathrm{D}$ printing of continuous carbon fiber prepreg filament. J Mater Sci 53(3):1887-1898. https://doi.org/10.1007/ s10853-017-1624-2

17. Sedighi A, Montazer M, Mazinani S (2018) Fabrication of electrically conductive superparamagnetic fabric with microwave attenuation, antibacterial properties and UV protection using PEDOT/magnetite nanoparticles. Mater Des 160:34-47. https:// doi.org/10.1016/j.matdes.2018.08.046
18. Feng X, Zhao Y, Jiang Y, Miao M, Cao S, Fang J (2017) Use of carbon dots to enhance UV-blocking of transparent nanocellulose films. Carbohydr Polym 161:253-260. https://doi. org/10.1016/j.carbpol.2017.01.030

19. Tan BH, Muiruri JK, Li Z, He C (2016) Recent progress in using stereocomplexation for enhancement of thermal and mechanical property of polylactide. ACS Sustain Chem Eng 4(10):5370-5391. https://doi.org/10.1021/acssuschem eng.6b01713

20. Fujii $T$, Matsui $Y$, Hirabayashi $H$, Igawa $K$, Okada $S$, Honma $H$, Nishimura H, Yamada K (2019) Influence of residual chlorine and pressure on degradation of polybutylene pipe. Polym Degrad Stab. https://doi.org/10.1016/j.polymdegradstab.2019.06.012

21. Cuadri AA, Martín-Alfonso JE (2017) The effect of thermal and thermo-oxidative degradation conditions on rheological, chemical and thermal properties of HDPE. Polym Degrad Stab 141:1118. https://doi.org/10.1016/j.polymdegradstab.2017.05.005

22. Rychlý J, Mosnáčková $K$, Rychlá L, Fiedlerová $A$, Kasza G, Nádor A, Osváth Z, Stumphauser T, Szarka G, Czaníková K, Chmela Š, Iván B, Mosnáček J (2015) Comparison of the UV stabilisation effect of commercially available processing stabilizers Irganox HP 136 and Irganox 1010. Polym Degrad Stab 118:10-16. https ://doi.org/10.1016/j.polymdegradstab.2015.04.007

23. del Teso Sánchez K, Allen NS, Liauw CM, Catalina F, Corrales T, Edge M (2015) Chemiluminescence studies on comparison of antioxidant effectiveness on multiextruded polyethylenes. Polym Degrad Stab 113:32-39. https://doi.org/10.1016/j.polym degradstab.2015.01.010

24. Larché JF, Bussière PO, Thérias S, Gardette JL (2012) Photooxidation of polymers: relating material properties to chemical changes. Polym Degrad Stab 97(1):25-34. https://doi. org/10.1016/j.polymdegradstab.2011.10.020

25. Cuadri AA, Martín-Alfonso JE (2018) Thermal, thermo-oxidative and thermomechanical degradation of PLA: a comparative study based on rheological, chemical and thermal properties. Polym Degrad Stab 150:37-45. https://doi.org/10.1016/j.polym degradstab.2018.02.011

26. Chen G, Shen D, Feng M, Yang M (2004) An attenuated total reflection FT-IR spectroscopic study of polyamide 6/clay nanocomposite fibers. Macromol Rapid Commun 25(11):1121-1124. https://doi.org/10.1002/marc.200400079

27. Wu Q, Liu X, Berglund LA (2002) FT-IR spectroscopic study of hydrogen bonding in PA6/clay nanocomposites. Polymer 43(8):2445-2449. https://doi.org/10.1016/S0032-3861(01)00810 $-2$

28. Rychlý J, Rychlá L, Fiedlerová A, Chmela Š, Hronec M (2014) Thermally and UV initiated degradation of polypropylene in the presence of 2,5 bis(2-furylmethylene) cyclopentanone and heterogeneous distribution of hydroperoxides assessed by non-isothermal chemiluminescence in nitrogen. Polym Degrad Stab 108:41-47. https://doi.org/10.1016/j.polymdegradstab .2014.05.022

29. Gardette M, Perthue A, Gardette J-L, Janecska T, Földes E, Pukánszky B, Therias S (2013) Photo- and thermal-oxidation of polyethylene: comparison of mechanisms and influence of unsaturation content. Polym Degrad Stab 98(11):2383-2390. https://doi. org/10.1016/j.polymdegradstab.2013.07.017

30. Martins JV, Artaxo P, Liousse C, Reid JS, Hobbs PV, Kaufman YJ (1998) Effects of black carbon content, particle size, and mixing on light absorption by aerosols from biomass burning in Brazil. J Geophys Res Atmos 103(D24):32041-32050. https://doi. org/10.1029/98jd02593

31. Yu Y, Yu JC, Yu J-G, Kwok Y-C, Che Y-K, Zhao J-C, Ding L, Ge W-K, Wong P-K (2005) Enhancement of photocatalytic activity of mesoporous $\mathrm{TiO}_{2}$ by using carbon nanotubes. Appl Catal A 289(2):186-196. https://doi.org/10.1016/j.apcata.2005.04.057 
32. Steffen R, Setyamukti H, Wallner G, Geretschläger K, Röder B (2017) Kinetics of degradation-induced polymer luminescence: polyamide under dry heat exposure. Polym Degrad Stab 140:114-125. https://doi.org/10.1016/j.polymdegradstab .2017.04.010

33. Jiang H, Lai N, Tang J, Tian X, Wei F, Bai W, Xu Y (2019) Effect of photo-oxidation on the emissive properties of truxene. J Photochem Photobiol A 369:195-201. https://doi.org/10.1016/j.jphot ochem.2018.09.028

34. Sargado JM, Keilegavlen E, Berre I, Nordbotten JM (2018) Highaccuracy phase-field models for brittle fracture based on a new family of degradation functions. J Mech Phys Solids 111:458489. https://doi.org/10.1016/j.jmps.2017.10.015
35. Kyutoku H, Maeda N, Sakamoto H, Nishimura H, Yamada K (2019) Effect of surface treatment of cellulose fiber (CF) on durability of PLA/CF bio-composites. Carbohydr Polym 203:95-102. https ://doi.org/10.1016/j.carbpol.2018.09.033

Publisher's Note Springer Nature remains neutral with regard to jurisdictional claims in published maps and institutional affiliations. 